\title{
Pop-up structures of Petrodonetska anticline and adjacent territories
}

\author{
Natalia Diachenko ${ }^{1, *}$, and Andrii Diachenko ${ }^{2}$ \\ ${ }^{1}$ Institute of Geotechnical Mechanics named by N. Poljakov of National Academy of Sciences of \\ Ukraine, 49005, Dnipro, Simferopolska Str., 2a, Ukraine \\ ${ }^{2}$ Vilnius Gediminas Technical University Lithuanian Academy of Sciences, 10223, Vilnius, \\ Saulètekio al., 11, Lithuania
}

\begin{abstract}
Presents the results concerning a comparative analysis of paleotectonic reconstructions of the tectonic conditions dynamics for the formation of local plicative deformations and faulting in the study of the macrostructure and its local separation using the example of the AlmaznoMarievskyi region. The formation conditions characteristics of the Petrodonetska anticline and adjacent territories were obtained. In the plan, they are located en echelon-like, which is associated with a shift. The structure of the latter indicates a thrusting of the sedimentary stratum layers from the center of the Donetsk trough to its northern periphery. The analysis of reconstruction results regarding the formation of the Lysychanska anticline on the border with the Severodonetskyi thrust and sections in experimental research of pop-up structures, reveals their similarity in structure and formation. With oblique convergence of blocks from the shear zone, a series of overlapping thrusts are extruded. A central graben arises within the transpressive shear zone, along its axis due to the divergent reverse faults in the arched uplift. A system of parallel thrust faults forms a ramp. The necessity of using the system modeling method (the finite element method), which improves the methods for predicting gas-containing tectonic elements in the pop-up structures, is justified.
\end{abstract}

\section{Introduction}

The vast majority of traditional geological analysis objects should be attributed to objects of nonlinear geology, the science of the differentiation, organization, order and structuring processes [1]. In recent years, from the standpoint of geodynamic systems nonlinearity - the fundamental features of their behavior, researchers have analyzed many polytypic and different-scale phenomena in seismology, geodynamics, geochemistry, and other sections of geological science. Geologists have proposed appropriate models of their occurrence and evolution mechanisms. In particular, geodynamic processes have a number of common features due to peculiarities of the lithosphere structure and mechanisms of initiation and flow. The modeling of nonlinear processes is associated with dynamic effects research. One of the nonlinear geodynamics directions is the stress field study and the simulation of its behavior in the volumes of the Earth's crust. The active study of tectonic structure parageneses and the accumulation of vast actual material either on dynamic situations

\footnotetext{
*Corresponding author: natalidyachenko1969@gmail.com
} 
(longitudinal or lateral contraction or tension), or on types of deformations (reverse fault, thrust, shear, folded, pure or simple shear, etc.) led to the understanding that we are dealing with a set of multi-level parageneses. Therefore, the knowledge of parageneses is improved by field observations, experimental and theoretical modeling as well as modeling using fullscale examples.

This problem gets particularly important when forecasting gas-containing structures in coal-bearing areas and their geotectonic control. For example, simultaneously with them the advanced (marginal) and rear deflections are formed correspondingly in autochtones of the frontal and rear thrust systems, known for their oil and gas bearing structures [2]. Asymmetrical folds are formed when moving along such thrusts, creating specific structures that morphologically do not meet anticlinoria and synclinoria criteria. Until recently, a balanced structural-geological model of such objects did not exist in fact. And, as a result, a new criteria for mineral exploration was not developed. Taking into account the controversial ideas about the tectonics of such regions, the only way to approach an unambiguous understanding of the structure is:

- a detailed study of its local objects structures;

- a comparison of the actual tectonic structure to the results of modeling on equivalent materials;

- an involvement of system modeling and optimization methods based on computer algebraization for the analysis of nonlinear structures (model of system reliability) [3, 4].

\section{Purpose}

Analysis of local tectonic structures of the Petrodonetska anticline and adjacent synclines and faults (Lysychanska anticline, Holubovska syncline, Severodonetskyi thrust) from the point of view of the formation of structures: pop-up (compression zones along major shifts), shear folding, ramps; comparison of the actual tectonic structure to simulation results on equivalent materials and graphic modeling, using the example of a section of the folded and dome structures regarding the Almazno-Marievskyi geological and industrial region in the northern parts of the Donbas.

\section{Methods}

To solve this problem, when studying the macrostructure, we used methods of cartographic material structural analysis, comparative analysis of paleotectonic reconstructions to the results of modeling on equivalent materials and mathematical modeling (close to geological data). Analytical comparative methods for the establishment of structural relationships between variables and permanent elements of the tectonic system under study.

\section{Results and discussion}

The main coal-bearing areas of the Donbas (Luhansk region) northern part are located in the strip of the small size folding northern zone. The north-eastern part of the AlmaznoMarievskyi district, which lies between the Severodonetskyi and Marievskyi thrusts, is a subzone of the dome folds. Here in the upper wall of the Severodonetskyi thrust, the carbonifer suite is complicated by a system of complex anticlinal structures separated by synclines and anticlines (Fig. $1 \mathrm{a}, \mathrm{c}$ ). According to its geostructural position, the territory is located in the northern zone of small sized folding of the Almazno-Marievskyi synclinorium of the Donetsk folding structure (DFS) on the Donetsk Basin border with precambrian crystalline rocks of the Voronezka anteclise between the Severodonetskyi and 
Marievskyi thrusts. From the north, the DFS from the Voronezka anteclise, according to deep seismic sounding, is separated by a system of deep suture faults [8], which continuation in the sedimentary cover formed two groups of regional discontinuities reflecting the fault structure of the foundation. The first group is traced under the Severodonetskyi and Kamenskyi thrusts, the second - under the Marievskyi thrust of the south-western fall, stretching eastward under the Hlybokynskyi thrust [9]. The founding of the Pivnichnyi marginal fault fragments, "which occurred abruptly and locally," is confined to the middle devonian [10]. According to the work data [11], which was carried out to study continental rifting, in particular, the phase of its inversion, the Pivnichnyi marginal fault is a flat-dipping primary rupture with a S-SW dip azimuth. To the Pivnichnyi of the Severodonetskyi thrusts, along the southern edge of the platform slope stands a chain of dome structures (Fig. 1, a). The North-Donbas deep rupture zone breaks down into two intersecting branches, traced under the Marievskyi and Hlybokynskyi, Severodonetskyi and Kamenskyi thrusts respectively [12]. The affiliation of the Marievsko-Hlybokynskyi thrusts to a single disjunctive system was demonstrated in the paper [9]. The studies [13] proposed a similar tracing of the Severodonetskyi and Kamenskyi thrusts - as a single faulting crossing the Marievsko-Hlybokynskyi disjunctive at an angle of about $20^{\circ}$. The Severodonetsk-Kamenskyi deep fault is divided by transverse faults into a number of separate fragments, turned clockwise relative to the crescent-extending axis of this deep structure bent to the south-west [14]. Just to the west of the Luhansk city, the first fragment turn is most noticeable, in the north-eastern periphery of which a Slavianoserbska structure is located. It is expressed as a horst anticline in the crystalline foundation. The band of anticlinal folds (Lysychansko-Marievskyi district) has a common northwest strike and consists of several separate structures, aggravated by faults (Fig. 1, a, b, c). The largest is the complexly constructed Dronovsko-Marievska anticline (DMA), which is the northeast side of the Bakhmut hollow. From N-NW it is sharply bounded by the Marievskyi thrust (MT), immediately followed by the Petrodonetska, Matrosko-Toshkovska (MTA), Lysychansk-Kremenska (LKA) anticlines, which are stretched in the NW direction. In the plan these anticlines are located en echelon-like; each more western one is shifted to the north relatively to the neighboring one. The size of each of them is successively decreasing from northwest to southeast. The arch of the DMA and its western side is complicated by folds, which axes are elongated in the latitudinal direction at an angle of $30^{\circ}$ to the main folds axes of the Donetsk strike. The northeast side is trimmed by MT. The plane of the depth fault is flattening out. Carbon offset amplitude is up to $2 \mathrm{~km}$, chalk is $0.5 \mathrm{~km}$, paleogene is up to $40 \mathrm{~m}$. LKA has a NW strike and asymmetric structure, the upstructure portion side is cut off by the Lysychanskyi thrust (amplitude up to $200 \mathrm{~m}$ ), the northeast side is torn apart by the Severodonetskyi thrust. The structure of these folds indicates that the layers of the sedimentary strata are thrusting from the center of the Donetsk deflection to its northern periphery. Apparently, there was some kind of protrusion (raising) of the sedimentary strata.

The LKA fold band has a number of uplifts and dives. As a result, the arch part of the fold is complicated by small gaps and transverse clamps and appears in the plan in a form of individual domes. MTA and Petrodonetska anticlines have common structural features. Deposits occur with angular unconformity. The unconformity reaches $45^{\circ}$ between carbon and triassic, and $15^{\circ}$ between triassic and chalk, $5^{\circ}$ between chalk and paleogene. The folds have a symmetrical structure. Their formation was accompanied by powerful dislocations with a break in continuity of a concordant upcast faults type in discharge with an amplitude of up to $700 \mathrm{~m}$, which developed not on one wing, but symmetrically and predominantly along the fold arches. With the plane depth of these steeply dipping faults they deviate towards the wing sides, cutting them off from the arches. 


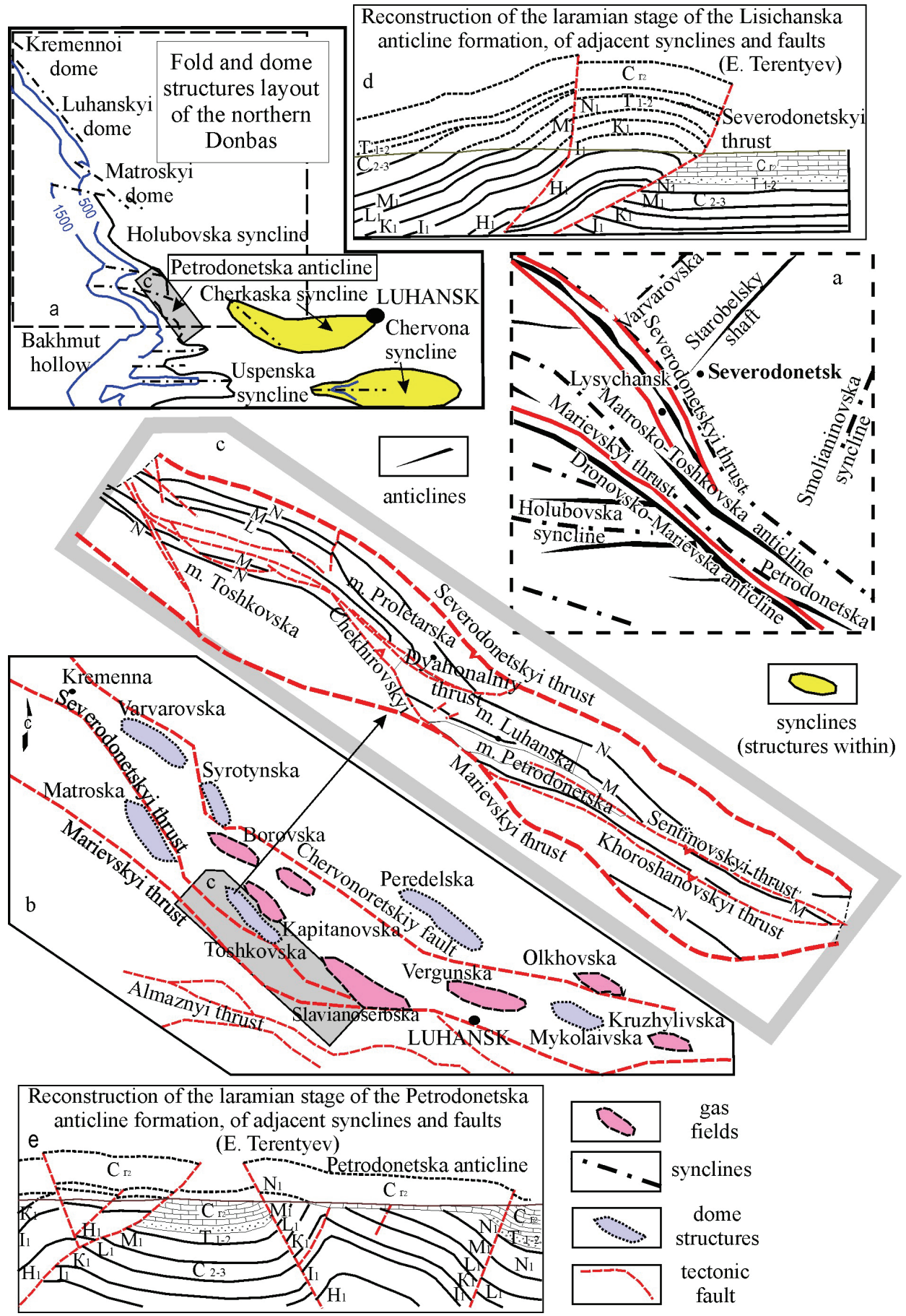

Fig. 1. Fold and dome structures layout of the northern and central Donbas with detailing of the tectonic structure and plicative structural organization (a) and local tectonic structure (c) within the northeastern coal-mining area of the Luhansk region according to work material [5]. Insets - detailing of dome structures and gas fields within the research area (c), reconstruction of the laramian stage of the Petrodonetska anticline formation, of adjacent synclines and faults (d) and adjacent Lysychanska anticline (e) by materials $[6,7]$. 
To the western pericline - the Matroskyi dome, thrusts fall towards each other, mutually intersecting and gradually descending from the arches to the wings. Apparently, a structure (the Matroskyi dome) of the wings thrusting on the arches by reverse faults is formed, which indicates a strong side contraction during the formation and "floating" of the structures.

A review of the previously performed studies on the nature of the gap manifestations within the northern zone of a small size folding indicates that the vast majority of largeamplitude faults is characterized by the predominant development of shear forms. In the paper [15] authors cite data on the syndepositional development of ruptures (Slavianoserbskyi, Hlybokynskyi, Kamenskyi) of the northern near edge zone with their subsequent transformation into thrusts formed as a result of reversing postsedimentary movements. In the paper [16], shear displacements along the North-Donbas deep-seated fault were considered, along which a right-shift activation took place at the post-folding stage of Donbas development. The predominance of the feathering opening fractures and feathering shear faults is highlighted in materials [17] during the study of large-amplitude thrusts (Ilichivskyi, Irminskyi) within the adjacent Sulino-Sadkinska syncline. At the same time, the linear angle of the dihedral angle, formed by the fault displacement surfaces of the feathering shear faults and thrusts, is $50-70^{\circ}$. The acute vertex of this angle is facing the direction of the coal-bearing strata movement along the thrust fault plane of displacement. Calculations of dynamic amplitude vectors for a number of regional ruptures of Northern Donbas (using lithologic-and-facies bench marks in shifted fault wings), given in the papers $[18,19]$, also made it possible to isolate the shear component of the displacement by gaps. The materials of the work [20], in which are analized the results of statistical processing of structural and geological data regarding the extent of fault traces within the mining concession of Luhansk mine, located in the Petrodonetsk anticline area in the zone of its junction with the Chekhirovska syncline, indicate the revealing of tectonic low-amplitude shifts. They are concentrated into conjugate tectonic bands and are characteristic for the shear stress field setting (the horizontal position of the main kinematic compressionrarefaction plane $\left(\sigma_{1}-\sigma_{3}\right)$, the position of the intermediate stress axis $\sigma_{2}$ is vertical). At the same time, the axis $\sigma_{1}$ is the axis of shortening of the space due to the horizontal shift in the horizontal plane, it is $0-15^{\circ}\left(180-195^{\circ}\right)$ azimuth oriented, the axis $\sigma_{3}$ (axis of elongation) is $90-105^{\circ}\left(270-285^{\circ}\right)$ azimuth oriented.

The most interesting, in this context of the study, are the paleotectonic reconstructions results of E. V. Terentyev [7] in the area of the Lysychanska anticline (Fig. 1, d, e), which led to the conclusion that a plicative structure developed into the saal phase of the hercynian orogeny, in the laramian phase of the alpine cycle, has turned into a structure of dragging and "moved to the north by $2500 \mathrm{~m}$ along the plane of fault displacement of the Severodonetskyi thrust". It was the shift that caused the formation of the structures of the gate on the northeast wing of the Lysychanska anticline. According to modern concepts, the nature of the turn of the stratum on the fracture wings indicates horizontal movement along the displacer. The Marievskyi thrust [6], which was formed during the novokommerian phase, has updated during the laramian folding phase, which led not only to the intensification of plicative structures but also to the formation of disjunctive dislocations.

The geological section through the Petrodonetska anticline and the Chekhirovska syncline (Fig. 1, e) has a length of $11 \mathrm{~km}$ and is oriented along the SW $40^{\circ}$ azimuth, and reflecting the recovery results of the structures formed during the laramian displacements period [6]. During that time there was a decrease in the stratigraphic amplitude of the Marievskyi gap. In the pre-triassic time, the general slope of the layers was directed to the north and was complicated by flexural-like bend. In the novokommerian phase, on the site of the paleosyncline flexure, the Marievskyi thrust emerged where the southern part of the section was "elevated 500-700 m relative to the northern one", and an anticlinal structure of 
the dragging type was formed in the hanging wall.

Shear experiments with compression and analysis of models, which either have a tectonic natural prototype, or are as close as possible to it, presented in the papers [21, 22]. They make it possible to evaluate not only the planned development of faults, but also the formation of fractured folding in the sections with the subsequent computer reconstruction of the 3D motion of individual massif elements (Fig. 2).
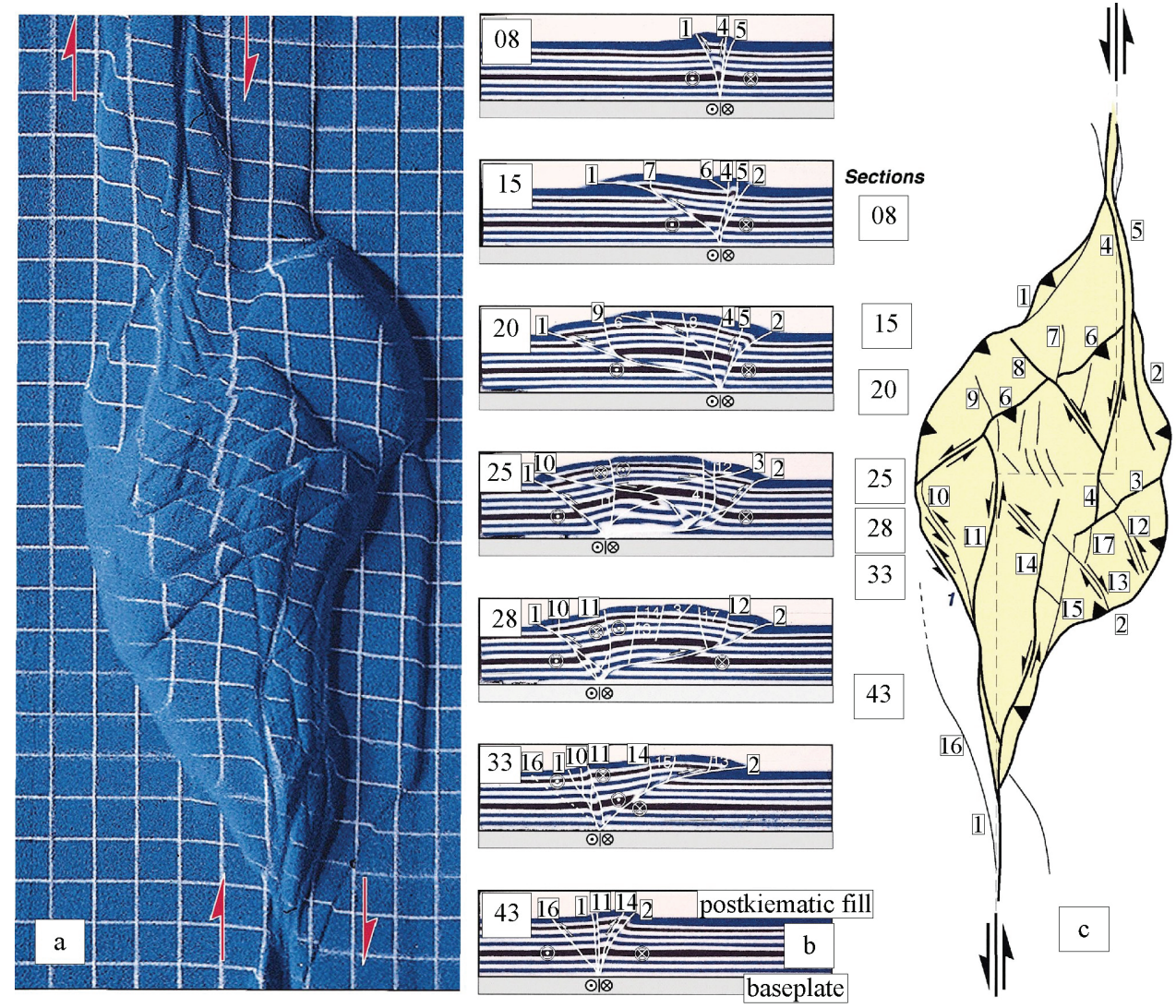

Fig. 2. Fifty serial sections were cut at $1 \mathrm{~cm}$ intervals across the model. Serial vertical sections and a line diagram of the surface of experiment after $10 \mathrm{~cm}$ sinistral strike-slip displacement on the basement fault system (a). Faults are numbered to permit correlation between the plan view diagram and the vertical sections (b). Sequential top-surface photographs showing the progressive evolution of experiment, 150 restraining stepover (e) $10 \mathrm{~cm}$ displacement [22].

The measured models of the artificial massif have successfully simulated geometry and progressive evolution of the antiformal pop-up structures developed in the sedimentation "cap" on the surface above the main shear of the strike-slip system in a rigid base. The oblique shear angle values varied in three models: $30^{\circ}-90^{\circ}-150^{\circ}$. Vertical and horizontal sectioning in different orientations (sections) of models was recorded photographically and converted into digital form (Fig. 2). The experimentally obtained pop-up structures have: sigmoidal or rhomboidal shapes; - geometry depending on the angle of slope and on the foundation base area in which the shear occurs; - mirror symmetry of structural tectonic forms about the axis, which is parallel to the axis of compression. In the lower part of the sedimentation model, the pop-ups are larger; when approaching the surface, the pop-up structures are usually narrower and resemble positive flower structures, on the surface they expand and become noticeably asymmetric. During the experiment, the maximum rotations 
of individual blocks in the left-shift zone were recorded under conditions of additional compression (transpression) from $7^{\circ}$ to $16^{\circ}$ while changing the cleavage angle from $30^{\circ}$ to $150^{\circ}$. Three-dimensional visualization of vertical section systems illustrates the structural difficulties and curvatures of the slip structures fall, which connect pop-ups (Fig. 2, a, c). The analysis of cartographic and analytical materials suggests the presence of such structures in the study area.

Until recently, asymmetric folds that morphologically do not correspond to anticlinoria and synclinoria did not have an unambiguous name. Since the 70 s of the last century, the term pop-up, which means "pop-up window", has been introduced. This term is used to refer to compression zones along major shears, where compression and tension structures alternate. At the same time, the structures of the divergent structure are naturally confined to the frontal parts of high-amplitude regional thrusts. In Ukraine, the pop-up structures in Donbas were identified [2] when analyzing maps and sections of the coal basin. According to the author, since the thrusts of the southern Donbas have a NE dip, and the northern Donbas has SW dip, and an active-marginal magmatism synchronous to the thrusts is located in southern Donbas, then in geodynamic model, Luhanskyi thrust groups should be considered as frontal thrusts, and south Donbas thrust groups should be considered as back thrusts. The small pop-up structures are registered according to seismic surveys and outcrops in allochthonous thrusts and back thrusts.

A comparative analysis regarding the reconstruction results of the Lysychanska anticline (section) formation at the border with the Severodonetskyi thrust (Fig. 1, d) and mirrorsymmetric sections 15, 33 (Fig. 2, b) in experimental studies [22] reveals their similarity in structure and, most likely, in formation. During the blocks' convergence, a series of small, overlapping thrusts are squeezed out of the shear zone. If a rigid block is present inside the shear zone, experiencing more or less homogeneous deformation, then two shear zones, practically parallel to each other, are formed. The thrusts are squeezed of them in different directions (the maximum number of tectonic plates is squeezed out towards the submerged block). At the same time, during the oblique convergence of blocks within the transpressive shear zone (with predominance of compression forces) along its axis, a central graben may occur due to divergent thrusts raising in the arch, which is precisely what we are witnessing (Fig. 1, e). The structural parageneses of shear compression zones are determined by a combination of tangential stresses acting along the general shear and compression stresses acting across the shear. As a result, the block, turned out to be in the zone of transpression, is crushed in the direction transverse to the shear surface and extends more often in the vertical direction, and less often in the horizontal direction [23]. Separate plates, squeezed out upwards from the shear zone, fall apart in different directions and form divergent series of uplifts and thrusts of floral structures with various morphological types. Consediment folds are often formed above faults. Systems of parallel discontinuities presented on Terentyev sections, which are formed in the setting of additional horizontal compression (a system of parallel uplifts, which is compressed across the plane of fault displacement and stretched in the vertical direction), form three types of structures: ramps - are symmetrical negative structures, bounded by a conjugate pair of diverging thrusts (Fig. 1, d); horsts are symmetric positive structures, bounded by a conjugate pair of oncoming upthrusts or systems of parallel thrusts; half-ramps - are asymmetric negative structures limited to one major thrust on the one hand, and on the other hand are represented by monoclines or oncoming flexures. This paragenesis includes nappes, buckling folds, and dragging folds, which, apparently, are associated with local gas fields in the analyzed area (Fig. 1, c). The involvement of system modeling and optimization methods on the basis of computer algebraization for analyzing nonlinear structures will allow us to look at the tectonic evolution from a mathematical point of view and improve the mathematical forecasting methods of gas-containing tectonic elements in pop-up structures. Within the framework of 
nonlinear dynamic concept, mathematically similar processes are described by nonlinear differential equations, which differ from linear ones, in particular, by the fact they have a unique (unique stationary) solution before certain values of parameters included in the equation. However, at the moment of transition, even if it's smooth, at least of one parameter (it is called a control parameter in such cases) through some critical value, the solution becomes multi-valued (the number of stationary solutions increases). This means that behavior of the system is being abruptly and qualitatively reconstructed. Consequently, the possible number of major factors or characteristics of geological model and typical diagnostic combinations of geological natural objects characteristics - should be evaluated, using the approaches of the group decision theory and the method of estimating the number of hidden factors and characteristics with internal dimension techniques. The search algorithm of the internal dimension was partially software implemented and used in Kazakhstan while analyzing the geological model for forecasting [24]. The problem of estimating the possible number of main factors or characteristics in this model has been solved using the Karhunen-Loeve (KL) series decomposition and with the help of internal dimension search algorithm. This transformation is optimal for the representation of continuous signals with respect to the criterion of the mean square error. If the system of random process eigenfunctions is chosen as an orthonormal basis, then the maximum information compression is achieved in a sense that entropy of the random process distribution energy is minimal. The main disadvantage of the KL-transform is the absence of fast calculation algorithms. The KL method does not have a wide application in handling of random process arrays with high dimensionality. This is due to the fact that computional costs are significant at all stages of the multistage optimization procedure. For this reason, the KL method is used to compress processes only with a low dimensionality of data arrays and a low degree of variability. Therefore, traditional decomposition methods are used in many practical problems: in traditional Fourier, Walsh, and Haar bases, which are computationally efficient.

When creating models, more attention should be paid to a better understanding of the model characteristics intristic to the system, rather than predicting specific actions of the specific system state in the future. The model should reproduce or predict the characteristics of the system behavior, such as: stability, oscillations, general interrelationships of variables, which are changing over time and caused by external causes. Moreover, a reduction in computational complexity is needed.

Most likely, similar problems of modeling objects in mountain massif real geodynamics, in the process of evolution, taking into account the oblique shear and additional compression, should be solved by the finite element method (FEM). The method is widely used for problem solving in deformable solid body mechanics, heat transfer, hydrodynamics, and electrodynamics. FEM is a numerical method for solving partial differential equations, as well as integral ones. We divide the area, in which the solution of differential equations is investigated, into a finite number of subdomains (elements). In each element a type of the approximating function is chosen randomly. In the simplest case, this is a first-degree polynomial. Outside its element, the approximating function is zero. Values of functions at the borders of elements (at the nodes) are the solution to the problem and are unknown in advance. The coefficients of the approximating functions are usually obtained from the condition of equality of neighboring function values at the boundaries between the elements (at the nodes). These coefficients then are expressed in terms of the values of functions in the nodes of elements. A system of linear algebraic equations is created. From the point of view of computational mathematics, the idea of the finite element method is that the minimization of variational problem functional is carried out on a set of functions, each of them is defined in its own subregion. For numerical analysis of the system, we can consider it as one of the specific branches of diakoptics, which is the 
general method of system research by their partitioning.

The principles of mathematical modeling are determined by the acceptability of a mathematical model to the compliance conditions of its properties to the properties of objects of modeling, by the natural objects structure complexity of gas accumulations and the limited empirical data that prevent the direct application of deterministic models. To identify the deterministic components, most models are based on a probabilistic basis, since most manifestations of studied properties random variability indicate not the absence of geological patterns, but the lack of data at the stage of the subsoil research. The combination of simulation results on equivalent materials with the research data of actual natural reference objects under conditions of mountain massif real geodynamics in the course of evolution and mathematical models will bring closer the forecast and search of gas fields in local structures within the shear zone that formed the pop-up structures.

\section{Conclusions}

Analysis of cartographic and analytical material suggests the presence of pop-up structures in the study area (Almazno-Marievskyi district), which are formed in compression zones along major shifts, where compression and extension structures alternate. A comparative analysis regarding the reconstruction results of Lysychanska anticline (section) formation on the border with the Severodonetskyi thrust and mirror-symmetric sections in experimental studies revealed a similarity in structure and, most likely, in formation. It is noted that under oblique convergence of blocks within the transpressive shear zone, when the compression forces predominating along its axis, a central graben arose at the contact with the Petrodonetska anticline due to divergent uplifts in the arched uplift. Systems of parallel discontinuities, presented on the sections (cuts), are formed in environment of additional horizontal compression. The system of parallel thrusts, which is compressed across the displacer and stretched in the vertical direction, has formed three types of structures: ramps, horst, half-ramps. This paragenesis includes buckling folds, subthrust drag folds, which, apparently, are associated with local gas fields in the analyzed area. We considered a necessity of improving the methods regarding the mathematical prediction of gas-containing tectonic elements in pop-up structures as a result of the system modeling and optimization methods involvement based on computer algebraization. The analysis of mathematical methods and techniques used to solve modeling problems has been completed. To solve tasks of object modeling in mountain massif real geodynamics in the process of evolution, taking into account the oblique shear and additional compression, it is proposed to use the finite element method. The combination of simulation results on equivalent materials with the research data of actual natural reference objects under conditions of mountain massif real geodynamics in the process of evolution and mathematical models will bring closer the forecast and searches for the gas fields in local structures within the shear zone that formed the pop-up structures.

\section{References}

1. Horiainov, P.M., Ivaniuk, G.Yu. (2001). Energy percolation is a resource of new ideas in geotectonics. Vesnik of Voronezh State University. Series geology, (11), 7-22

2. Yudin, V.V. (2010). Pop-up structures in tectonics of the world and Southern Ukraine. 8th international conference "Crimea - 2009", 51-68

3. Minkevicius, S., Kulvietis, G. (2005). Reliability in Computer Networks. System Modelling and Optimization, 295-300 
4. Cepulkauskas, A., Kulvietiene, R., Kulvietis, G. (2003). Computer Algebra for Analyzing the Vibrations of Nonlinear Structures. International Conference on Computational Science, 747-753

5. Pesotskyi M.F. (2004). Lugansk region. Atlas. Kyiv: Kartographia, 31

6. Amosov, I.I., Velikanova, M.V., Ivanov G.A. (1978). Geology of coal and shale oil deposits in the USSR (12). Moskva: Nedra

7. Terentyev, E.V. (1976). Paleotectonic reconstructions on geological sections as an analysis of the history of the structure formations and tectonic movements. Tectonics of coal basins and deposits of the USSR (5). Moskva: Nedra

8. Sollogub, V.S., Borodulin, M.I., Chekunov, A.V. (1977). The deep structure of Donbas and adjacent regions. Geologicheskii zhurnal, (2), 23-31

9. Raznitsyn, V.A. (1975). Tectonic zoning and genesis of the North zone structures with small size folding. Geotektonika, (2), 57-72

10. Bulat, A.F., Zviahilskyi, E.L., Lukinov, V.V., Perepelytsia, L.I., Pymonenko, L.I. (2008). The carbonaceous massif of Donbas as a heterogeneous environment. Kyiv: Naukova dumka

11. Stovba, S.N., Tolkunov A.P., Stifenson, P.A., Bagger, Yu. (2002). The deep structure of the Donetsk orogen according to the data of CDP on the profile of DOBRE-2000. Naukovyi visnyk Natsionalnoho hirnychoho universytetu, (4), 86-98

12. Pryvalov, V.O. (2005). Tectonothermal evolution of the Donetsk basin. Abstract of the dissertation for the Doctor of Geological Sciences degree. Specialty 04.00.16. Dnipropetrovsk, 35

13. Pryvalov, V.A., Zhykaliak, N.V., Ovcharenko V.A., Panova O.A. (2002). The intensity ratio of different-age tectonic movements along the regional gaps of the Donbas Northern Margin. Mineralni resursyi Ukrainyi, (8), 21-23

14. Pryvalov, V.A. (1998). The rotation of blocks and scenario of the Donetsk Basin tectonic evolution. Heolohyia i heokhimiia horiuchykh kopalyn, (4), 142-158

15. Nahorniy, Yu.N., Nahorniy, V.N., Zemlianoi, B.P. (1973). On the role of constipation tectonic movements in the formation of Donetsk Basin folded structures. Geotektonika, (5), 107-117

16. Smichko, R.M. (1985). The main faults of the Donetsk Basin and associated shears. Geotektonika, (2), 120-125

17. Shkurskiy E.F. (1980). On discontinuities, feathering medium- and large-amplitude thrusts. Ugol Ukrainyi, (11), 46

18. Mikhalev A.K. (1988). On horizontal component of the Kamensky thrust amplitude in Donbas. Geologicheskii zhurnal, (1), 127-129

19. Mikhalev A.K. (1978). About faults in surface sediments of Krasnoarmeysky district of Donbas. Geologicheskii zhurnal, (2), 57-72

20. Diachenko, N.A., Pryvalov, V.A. (2011). Low-amplitude tectonics of the Petro-Donetsk anticline (using as an example Luganskaya mine). Naukovi pratsi UkrNDMI NAN Ukrainy, (8), 163-176

21. McClay, K.R., Rutter, E.H., Knipe R.J. (1990). Deformation mechanics in analogue models of extensional fault systems. Deformation mechanisms, rheology and tectonics: Geological Society Special Publication (54), 445-454

22. McClay, K., Bonora, M. (2001). Analog models of restraining stepovers in strike-slip fault systems. AAPG Bulletin (85), (2), 233-260

23. Tevelev, Al.V., Kosheleva, I.A., Khotylev, A.O., Prudnikov, I.A., Tevelev, Ark.V. (2015). The Data on the Composition and Age of the Kozlinogorsk Gabbro-Alkaline Granite Complex on the Western Slope of the Southern Urals. Moscow University Geology Bulletin. (70), (4). 338-349 
24. Bekzhanov, G.R., Buhaiets, A.I., Los V.L. (1987). Geological models in the prediction of mineral resources. Moskva: Nedra 